\title{
Um marcador de tempo alternativo para o estudo de movimentos uniformes e uniformemente acelerados
}

\author{
An alternative time marker for the study of the \\ uniform and uniformly accelerated movements
}

Osmar Henrique Moura da Silva ${ }^{1}$; Carlos Eduardo Laburú ${ }^{2}$

\begin{abstract}
Resumo
Este trabalho apresenta um tipo de marcador de tempo, montado com materiais de baixo custo, destinado ao estudo de movimentos uniformes e uniformemente acelerados pela força gravitacional. Um mecanismo para medir a freqüência desse marcador de tempo é a ele acoplado com a função de poder encontrar o valor (aproximado) da aceleração da gravidade local. O experimento, que é adequado para ser usado nas aulas de cinemática, também pode ser apresentado em feira de ciências pelos alunos, por ser um fator estimulante ao envolver certa participação dos estudantes em sua construção.

Palavras-chave: Marcador de Tempo, Experimento de Cinemática, Aceleração da Gravidade.
\end{abstract}

\begin{abstract}
This work presents a type of time marker set up with materials of low cost for the study of uniform movements as well as those accelerated by gravitacional force. A mechanism used to measure its frequency is coupled to it in order to find the approximate value of the acceleration of the local gravity. The experiment, that is adapted to be used during a kinematics class, can also be presented by the students at a science fair, for being a stimulating factor as it involves the students' participation in its construction.
\end{abstract}

Key Words: Time Marker, Cinematic Experiments, Gravity Acceleration.

\section{Introdução}

O marcador de tempo, experimento antigamente comercializado pela Funbec, foi desenvolvido para o estudo de movimentos uniformes e uniformemente acelerados. Ele é constituído de uma ponta vibradora que se choca com um papel carbono sobre uma fita a ser marcada. Assim, com uma massa suspensa por um fio que passa por uma roldana e que se conecta

\footnotetext{
${ }^{1}$ Físico; Laboratório de Instrumentação em ensino de Física, Departamento de Física, UEL. Email: osmarh@uel.br.

${ }^{2}$ Prof. Dr.; Departamento de Física, UEL. Departamento de Física, Universidade Estadual de Londrina, CEP 86051-970, Cx. P. 6001, Londrina, PR.

3 Fundação Brasileira para o Desenvolvimento do Ensino de Ciências.
} 
na fita, realiza-se uma experiência em que se verifica, por meio de um certo tipo de gráfico, que o movimento (do objeto) é uniformemente acelerado. Neste trabalho, apresentamos um marcador de tempo que pode ser construído com materiais de baixo custo, facilmente encontrados no comércio. Esse marcador de tempo mostra algumas vantagens em relação àquele desenvolvido pela Funbec: 1) o industrializado necessita de pilha para funcionar enquanto o aqui proposto é adaptado à energia elétrica da rede; 2) o novo marcador apresenta um novo sistema de marcação que utiliza uma caneta, o que evita a perda de pontos na fita, como algumas vezes acontece no marcador da Funbec, que usa papel carbono; 3) o equipamento da Funbec provê um número limitado de rolos de uma fita especial para a marcação, insubstituível caso acabe. O nosso marcador de tempo usa como fita para marcação a serpentina de carnaval.

Além das vantagens mencionadas acima, ao equipamento pode ser acrescentado um mecanismo elaborado a fim de, ao determinar a freqüência do marcador, encontrar o valor aproximado da aceleração da gravidade local. Também com esse mecanismo podem-se estudar movimentos uniformes, enquanto no experimento da Funbec, o "movimento uniforme" da fita (para calibrar o marcador e encontrar o valor da aceleração da gravidade local) é feito manualmente.

Apesar de existirem várias maneiras de encontrar o valor aproximado da aceleração da gravidade local, estamos propondo uma alternativa para um professor interessado em aulas experimentais no curso de cinemática.

\section{O equipamento}

\section{Material utilizado}

Marcador de tempo:

- Um pedaço de $4 \mathrm{~cm}$ de comprimento de um núcleo de ferrite com diâmetro de $1 \mathrm{~cm}$ (encontrado facilmente no interior de um radio velho ou em lojas de componentes eletrônicos).
- Fio de cobre esmaltado no 30 .

- Um transformador de $110 \mathrm{~V}$ para $12 \mathrm{~V}$ (facilmente encontrado nos camelódromos a baixo custo).

- Uma chave liga-desliga.

- Sistema vibratório:

- Pedaços de chapa de ferro de 0,6mm de espessura: $(5 \times 1) \mathrm{cm},(4 \times 1) \mathrm{cm},(2 \times 1) \mathrm{cm}$, $(4 \times 0,5) \mathrm{cm},(1,5 \times 0,5) \mathrm{cm},(2 \times 1) \mathrm{cm}$.

- Uma chapa de ferro de $2 \mathrm{~mm}$ de espessura, $8 \mathrm{~cm}$ de comprimento e $1 \mathrm{~cm}$ de largura.

- Um parafuso de diâmetro próximo de $3 \mathrm{~mm} \mathrm{e}$ comprimento de $3 \mathrm{~cm}$.

Dois pedaços pequenos de chapa de aço: espessura de $0,1 \mathrm{~mm}$, largura de $5 \mathrm{~mm}$ e comprimento de $10 \mathrm{~mm}$.

- Pedaços de madeira: $(15 \times 15 \times 2) \mathrm{cm} ;(8 \times 8 \times 2) \mathrm{cm}$; $(4 \times 8 \times 2) \mathrm{cm}$.

- Um pedaço de fórmica $(8 \times 8 \times 2) \mathrm{cm}$.

- Parafusos para madeira.

Clips cujo arame de ferro tenha um diâmetro de $1 \mathrm{~mm}$.

- 2 pregos com cabeça de aproximadamente $5 \mathrm{~mm}$ de diâmetro.

- Uma canetinha de cor de $5 \mathrm{~cm}$ de comprimento (cortada).

- Serpentina de carnaval.

- Sistema de suspensão do objeto a ser acelerado:

- Uma roldana com diâmetro externo de $5 \mathrm{~cm}$ e espessura total de $5 \mathrm{~mm}$. O diâmetro interno é de $4,5 \mathrm{~cm}$ com espessura no rasgo de $3 \mathrm{~mm}$. Obs.: dimensões aproximadas.

- Um eixo de ferro por onde se fixa a roldana acima.

- Barbante fino.

- Um pequeno cilindro de ferro com um gancho (de aproximadamente 400g). 
Mecanismo elaborado para estudos de movimentos uniformes e para encontrar o valor aproximado da aceleração da gravidade local:

- Duas molas pequenas.

- Uma tábua de $(100 \times 6 \times 1) \mathrm{cm}$.

- $50 \mathrm{~cm}$ de vareta de ferro cujo diâmetro é de $3 \mathrm{~mm}$.

- Adesivo Epóxi (tipo Durepóxi).

- 2 lâminas de barbear.

- Um motorzinho de $1,5 \mathrm{~V}$ (pode ser obtido em brinquedos sem uso).

- Arame de ferro (reto) com diâmetro de aproximadamente $1 \mathrm{~mm}$.

- Uma roldana de $4,5 \mathrm{~cm}$ de diâmetro externo, $4,2 \mathrm{~cm}$ de diâmetro interno, $6 \mathrm{~mm}$ de espessura total e $3 \mathrm{~mm}$ de espessura no rasgo (pode ser construída em um torno). Essa roldana deve possuir um furo central com diâmetro igual ao do arame de ferro.

- Uma roldana de $2 \mathrm{~cm}$ de diâmetro externo, $1,7 \mathrm{~cm}$ de diâmetro interno, $6 \mathrm{~mm}$ de espessura total e $3 \mathrm{~mm}$ de espessura no rasgo (pode ser construída em um torno). Essa roldana deve possuir um furo central com diâmetro igual ao diâmetro do eixo do rotor do motorzinho.

- Um elástico comum para servir de correia entre as roldanas.

- Pilha de $1,5 \mathrm{~V}$.

- Dois rolos (de plástico ou madeira) com diâmetro de $3 \mathrm{~cm}$ e $2 \mathrm{~cm}$ de comprimento. Cada um com um furo central longitudinal de diâmetro igual ao do arame de ferro. Esses rolos e os seus respectivos furos podem ser feitos no torno.

- Serpentina de carnaval.

- Adesivo líquido instantâneo (tipo Super Bonder).

- Uma chapinha de ferro: $(4 \times 2) \mathrm{cm}$ e $1 \mathrm{~mm}$ de espessura.

\section{Construção}

\section{Marcador de tempo}

O marcador de tempo possui um sistema vibratório de freqüência constante com a função de realizar marcas em uma fita a ser analisada. $\mathrm{Na}$ seqüência, apresentamos a construção desse sistema.

As cabeças dos dois pregos são lixadas com o auxílio de um esmeril de pedra de grana fina (para amolar ferramentas) de modo a ficarem com curvaturas lisas. Após isso, cortar os pregos, separando as cabeças que serão usadas na montagem.

Com as peças de ferro e aço já descritas (ver material utilizado) para tal montagem, construir as seguintes peças apresentadas nas figuras 1,2 e 3 . Observar nas figuras que algumas peças são entortadas. A caneta é presa por uma peça de ferro curva que se fecha com um parafuso. Todas as peças de ferro e aço, inclusive as cabeças dos pregos, são soldadas com uma solda ponto. Esse tipo de solda é facilmente encontrado em uma serralheria. Como são poucos pontos (ou soldas) a serem feitos nas montagens, rapidamente as peças podem ser unidas.

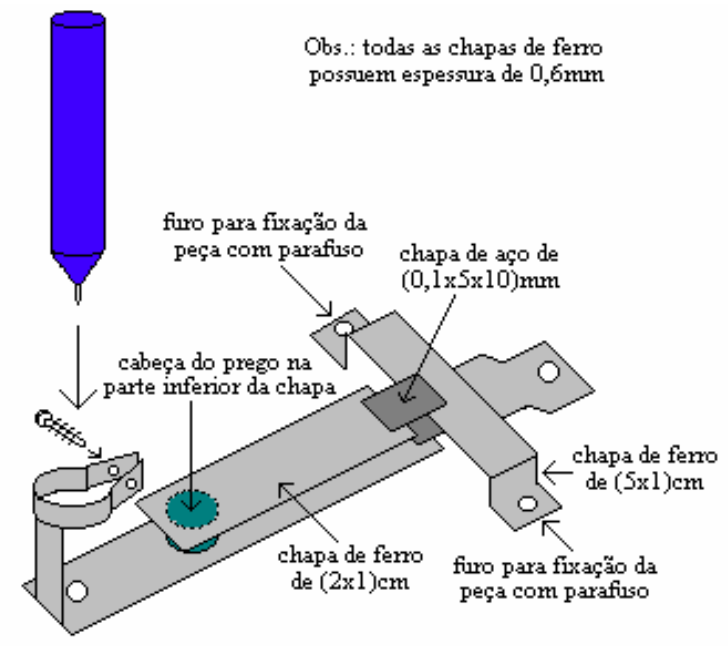

Figura 1 - Peça inferior do sistema vibratório. 


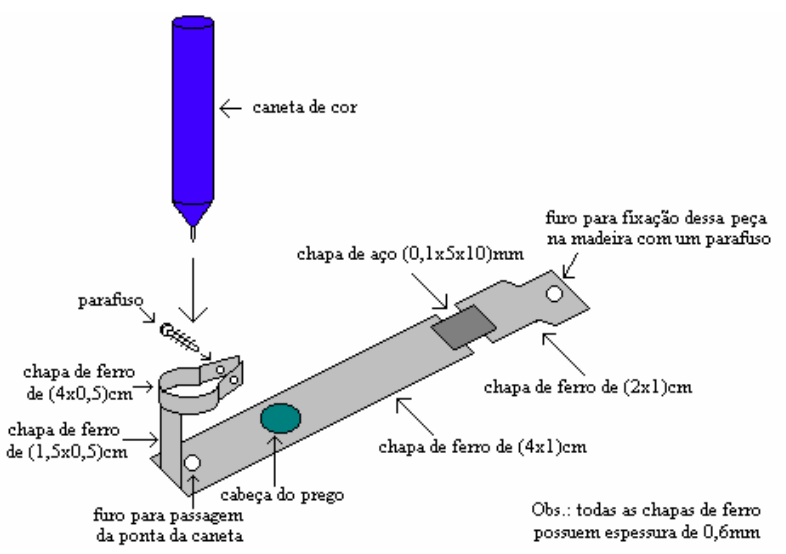

Figura 2 - Peça intermediária do sistema vibratório.

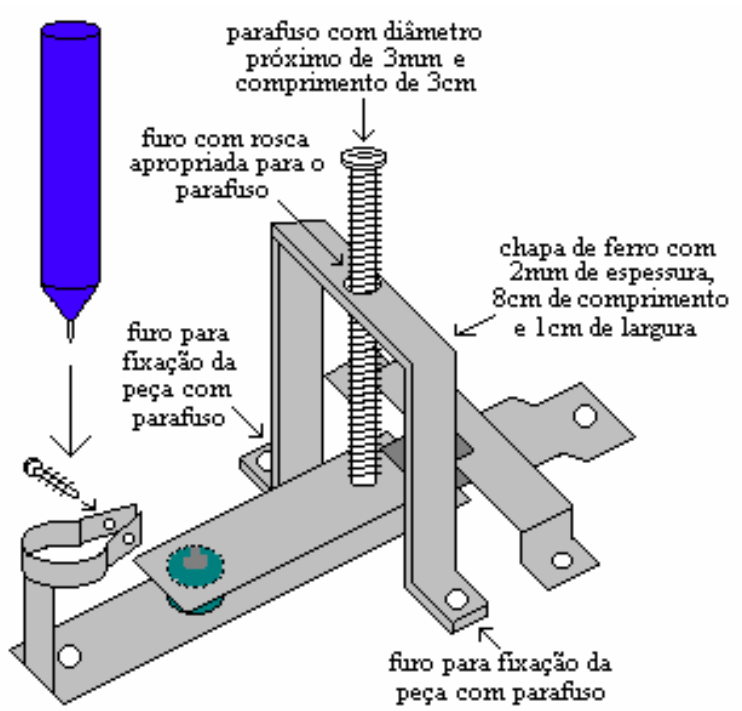

Figura 3 - Peça superior do sistema vibratório.

A peça adicionada na Figura 3 tem a função de apertar o parafuso e fechar o circuito, encostando as curvas das cabeças dos pregos. Todas as peças são parafusadas na peça de madeira de dimensões $(8 \times 8 \times 2) \mathrm{cm}$ (ver Figura 5). É necessário que a superfície superior dessa peça seja de fórmica para evitar atritos entre a fita e possíveis fiapos de madeira. Construir um eletroímã usando o núcleo de ferrite e o fio de cobre esmaltado no 30 . Para isso, montar uma bobina em torno desse núcleo com um total de aproximadamente 1000 espiras. Fazer um furo na madeira para encaixar o eletroímã. Esse furo é feito de modo que o eletroímã se posicione embaixo da cabeça do prego da peça inferior, conforme se vê na
Figura 4. Também nessa figura são apresentadas as ligações entre o sistema vibratório, o eletroímã e o transformador. Uma chave liga-desliga pode ser usada.

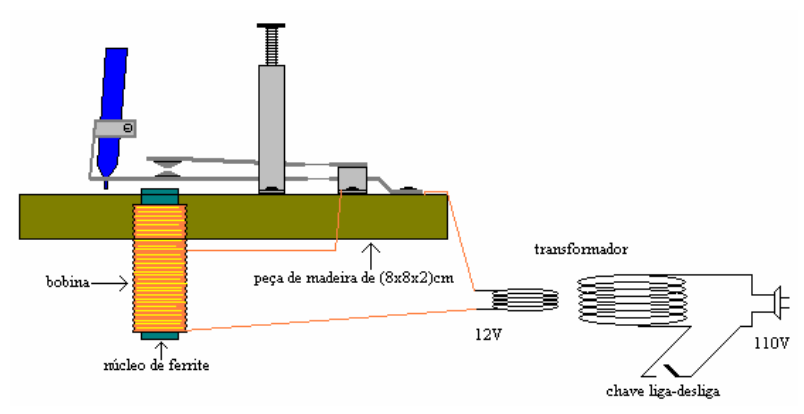

Figura 4 - Fixação das três peças da Figura 3 na madeira e apresentação das ligações entre o eletroímã, o transformador e o sistema vibratório.

Na Figura 5, são mostrados os dois direcionadores por onde passam as fitas utilizadas nas experiências. Eles são feitos com clips de $1 \mathrm{~mm}$ de diâmetro e alinhados conforme a posição da ponta da caneta. Na madeira são feitos furos para encaixá-los e ajustálos com uma folga de $3 \mathrm{~mm}$ da base com fórmica. $\mathrm{Na}$ base de madeira de $(15 \times 15 \times 2) \mathrm{cm}$ pode ser feito o seguinte arranjo do material utilizado e construído:

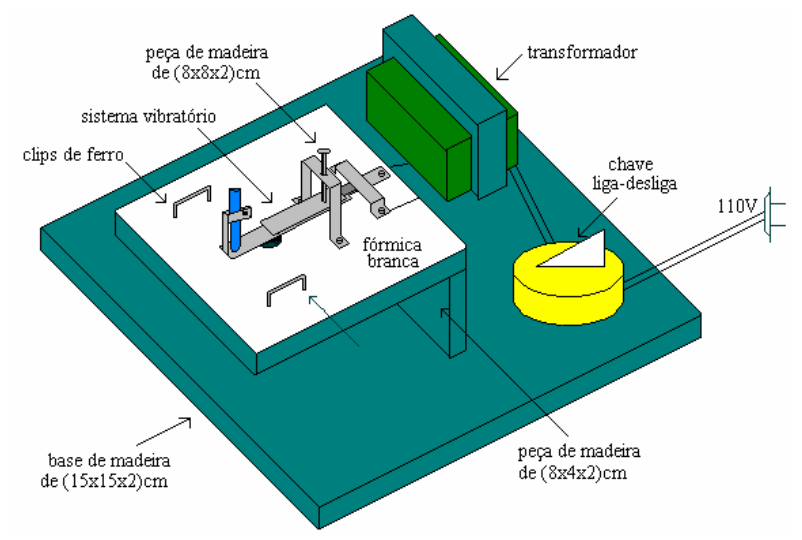

Figura 5 - Marcador de tempo montado.

Uma roldana presa em um eixo e suspensa a uma certa altura (mínima de $2 \mathrm{~m}$ ) também é necessária para que se realizem as experiências (mais adiante, na Figura 8). 
Mecanismo elaborado para estudos de movimentos uniformes e para encontrar o valor aproximado da aceleração da gravidade local

Para construir os mancais (onde se apóiam os eixos giratórios), usam-se a lâmina de barbear, o adesivo epóxi e a vareta de ferro com diâmetro de $3 \mathrm{~mm}$. Como o centro das lâminas de barbear comuns possuem furos com diversos ângulos, pode-se aproveitá-los na construção dos mancais como é visto na Figura 6:

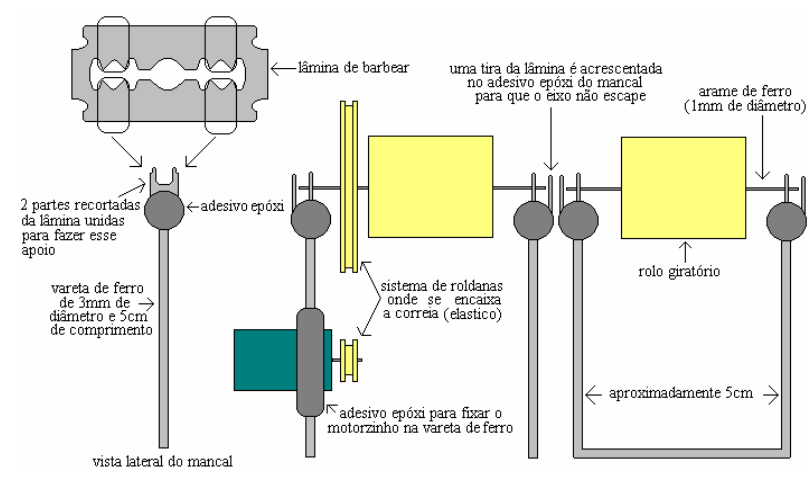

Figura 6 - Construção dos mancais e disposição das demais peças.

A roldana menor é encaixada e colada com o adesivo líquido na parte externa do eixo do rotor do motorzinho. A roldana maior é encaixada e colada em um dos eixos com rolos. O motorzinho é fixado com adesivo epóxi na vareta de ferro, de modo a ajustar o sistema de roldanas onde o elástico serve como correia.

Dessa forma, existem dois pares de mancais: o primeiro é onde se encontra o motorzinho com o sistema de roldanas e o segundo é apresentado à direita da Figura 6.

O mancal do motorzinho é fixo em uma das extremidades da tábua de $(100 \times 6 \times 1) \mathrm{cm}$. O segundo mancal é móvel devido a uma chapinha metálica que o segura na madeira com certa folga, posicionandose na outra extremidade. Nesse mancal móvel são acrescentadas as molas com a função de esticar a correia (fita a ser marcada). Essas molas são encaixadas em varetas fixas. A Figura 7 apresenta esse mecanismo montado.

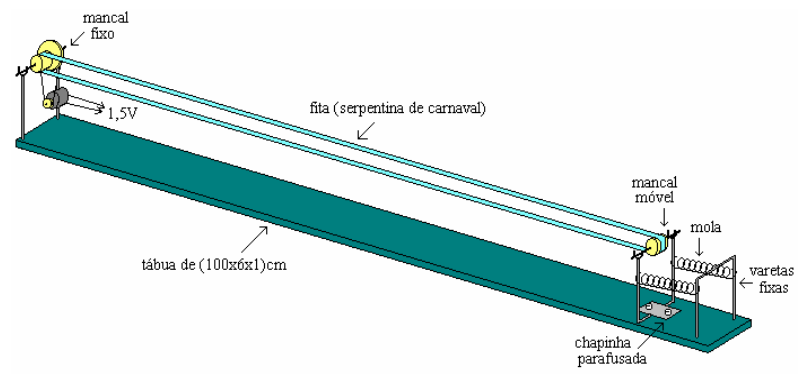

Figura 7 - Mecanismo para medir a freqüência do marcador de tempo alternativo

\section{Procedimento}

Parte 1 - Construção de gráficos e avaliação do tipo de movimento

Com os materiais já especificados na seção material utilizado, para o sistema de suspensão do objeto a ser acelerado, seguir os seguintes passos:

1) Deixar a roldana (cujo eixo está fixo em uma haste) a uma altura de no mínimo $2 \mathrm{~m}$.

2) Amarrar um pedaço de $2 \mathrm{~m}$ de barbante no gancho do cilindro de ferro.

3) Suspender esse cilindro, puxando o barbante através da roldana.

4) Amarrar a extremidade desse barbante com fita adesiva (tipo fita crepe) numa extremidade de $2 \mathrm{~m}$ de fita (serpentina de carnaval).

5) Passar os $2 \mathrm{~m}$ da fita nos direcionadores (clips) do marcador de tempo, deixando o início da fita embaixo da caneta. A Figura 8 apresenta a montagem através desses passos.

6) Ajustar a freqüência desejada do marcador sobre a fita, soltando-a em seguida juntamente com o cilindro em queda livre. 


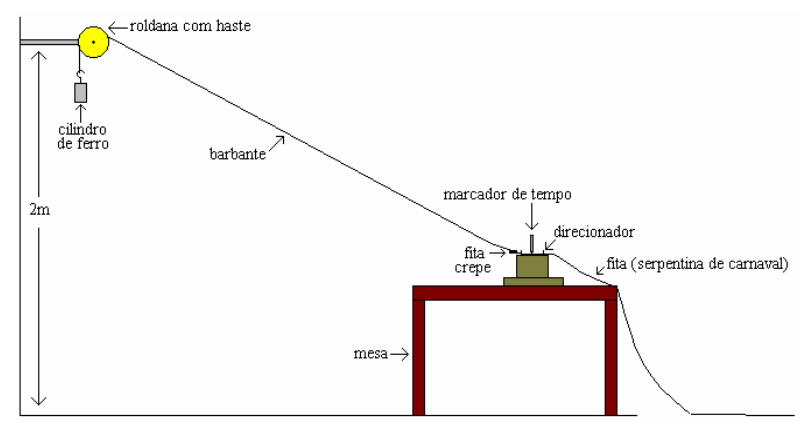

Figura 8 - Montagem do experimento para aceleração do objeto suspenso.

Dependendo da freqüência do marcador, pode-se encontrar um total de 30 pontos marcados na fita. Para analisar o movimento realizado pelo cilindro, não é necessário conhecer a frequiência do marcador, podendo-se convencionar, cada duas batidas do marcador com um intervalo de tempo de um tique. As medidas podem ser feitas a partir de três tiques. De três em três tiques (o que dá um total de aproximadamente 10 dados), faz-se a anotação em uma tabela da distância entre eles usando uma régua, conforme a seguinte Figura.

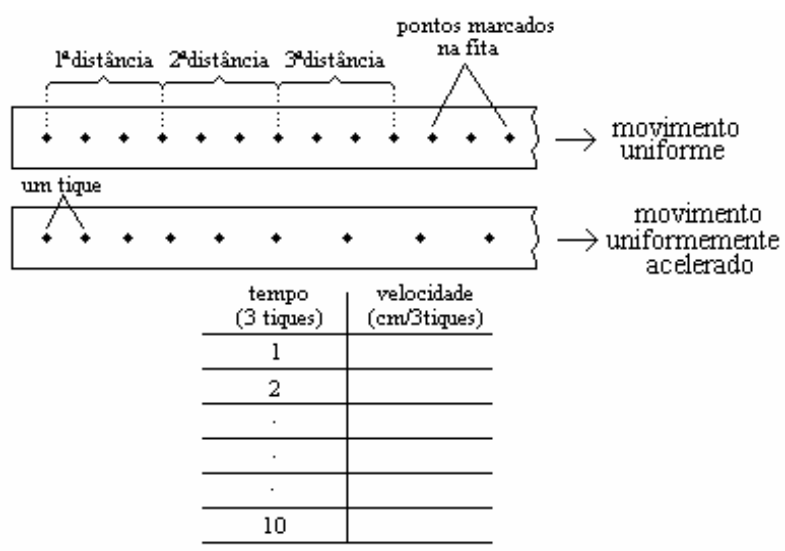

Fonte: Funbec (1977, p.15-17)

Figura 9 - Exemplo apresentado de pontos marcados sobre a fita em estudos de movimentos uniformes e uniformementes acelerados.

Constrói-se o gráfico da velocidade em função do tempo com os dados da tabela apresentada na Figura 9 e analisa-se o tipo de movimento do cilindro. Em seguida, pode-se calcular a aceleração da gravidade, determinando o coeficiente angular da reta média traçada entre os pontos. Dessa forma, é encontrada a aceleração da gravidade $\mathrm{em} \mathrm{cm} /(3 \text { tique })^{2}$.

Parte 2 - Estudo de um movimento com velocidade uniforme

Acoplar o marcador de tempo (Figura 5) no mecanismo apresentado na Figura 7. Para isso, a serpentina de carnaval deve passar pelos direcionadores do marcador e pelos rolos nos mancais com as extremidades unidas com um pedaço de fita adesiva. É preciso fazer um teste com o motorzinho ligado para verificar se a fita realiza voltas completas sem atritar e/ou travar nos direcionadores. A Figura 10 apresenta essa montagem.

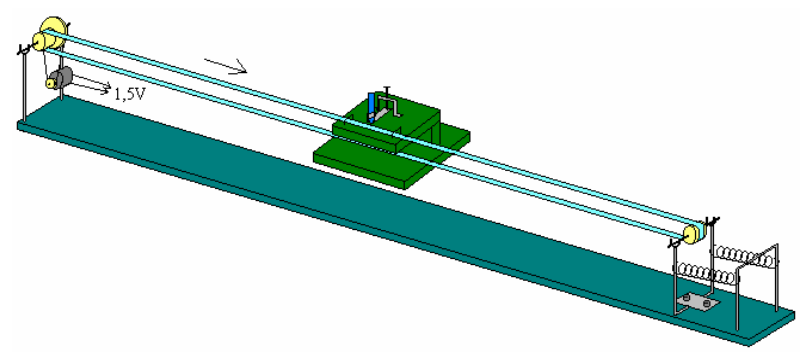

Figura 10 - Marcador de tempo acoplado no mecanismo medidor de freqüência

Por ser o movimento do motorzinho uniforme, pode-se estudar esse tipo de movimento analisando as marcações realizadas na fita por meio dos espaços, entre pontos desejados com o auxílio de uma régua, relacionando-os com seus intervalos de tempo por meio de um cronômetro.

Construir um gráfico de velocidade em função do tempo. Esse gráfico deve dar uma reta paralela ao eixo do tempo.

Observações: Como existe um sistema de roldanas nesse mecanismo, a velocidade uniforme da fita não é a mesma do motorzinho. A velocidade constante da fita e, diretamente, a do motorzinho, pode ser alterada com o acréscimo de uma pilha de 1,5V (como a experiência é rápida, o motorzinho 
não estraga) ou trocada por pilhas mais velhas, diminuindo a velocidade.

Parte 3 - Determinação da aceleração da gravidade

Para determinar o valor da aceleração da gravidade, é necessário conhecer o valor da freqüência do marcador de tempo. Para isso, realizar a experiência da montagem apresentada na Figura 10. Nessa experiência, ajuste o parafuso vertical acionando o marcador com uma certa frequiência ${ }^{4}$ (alta ou baixa - cujo valor será encontrado). Cronometrar o tempo gasto pela fita durante uma volta. Contar o número de pontos marcados na fita nesse intervalo de tempo e, assim, determinar quantos pontos faz o marcador no intervalo de 1 segundo (ou seja, a freqüência do marcador).

Com essa informação, seguir todos os passos mencionados na Parte 1. A seguir, construir um gráfico de velocidade em função do tempo com os dados da tabela que agora possui valores da velocidade $\mathrm{em} \mathrm{cm} / \mathrm{s}$ e do tempo em $\mathrm{s}$. Encontrar o valor da aceleração da gravidade $\left(\mathrm{em} \mathrm{cm} / \mathrm{s}^{2} \mathrm{ou} \mathrm{m} / \mathrm{s}^{2}\right)$ determinando o coeficiente angular da reta.

\section{Funcionamento do marcador de tempo}

Inicialmente, é feito um contato entre as duas chapas de ferro, aproximando-as com o uso do parafuso vertical. Esse contato fecha o circuito e um campo magnético, fortalecido pelo núcleo da bobina e que surge juntamente com a corrente elétrica ${ }^{5}$ na mesma, interage com as chapas de ferro (ferromagnéticas) atraindo-as para baixo. As chapas de ferro são afastadas uma da outra, pois, além da força de atração ser maior na chapa inferior devido à maior proximidade com o campo magnético do núcleo, a pequena chapa de aço conectada à chapa de ferro superior faz com que esta última exerça uma força com sentido para cima, ou seja, pressionando a extremidade do parafuso vertical, mantendo-a imóvel. Dessa forma, o circuito é aberto interrompendo a corrente elétrica da bobina, o campo magnético e a força de atração. Como a chapa de ferro inferior também possui uma pequena chapa de aço, ela retorna à posição inicial fechando o circuito novamente. Isso gera uma nova atração de origem magnética e faz com que o movimento da chapa de ferro inferior se repita com certa freqüência.

A frequiência deste marcador de tempo pode ser ajustada (manipulando o parafuso vertical) ao variar a distância entre a chapa de ferro inferior e a extremidade superior do núcleo da bobina. A pequena chapa de aço soldada na chapa de ferro inferior tem a função de retorná-la à posição inicial. Juntamente com a caneta, que é acoplada, o sistema possui uma freqüência natural de oscilação que determina a velocidade do seu retorno, indo ao encontro da chapa de ferro superior. Se a distância entre a chapa de ferro inferior e a extremidade do núcleo da bobina forem diminuídos pelo parafuso vertical, a força de atração é aumentada e a distância do retorno diminuída. Isso aumenta a freqüência do marcador e, em caso contrário, diminui.

\section{Alguns resultados \\ Parte 1 \\ Por meio da reta média traçada pelos pontos do gráfico, pode-se verificar que a velocidade do cilindro (ou da fita) aumentou linearmente com o tempo, o que caracteriza um movimento uniformemente acelerado.}

\footnotetext{
${ }^{4}$ Após isso, o parafuso não deve ser novamente manipulado até o final da experiência para não alterar a freqüência do marcador

${ }^{5}$ Alternada com freqüência de $60 \mathrm{~Hz}$, neste caso.
} 

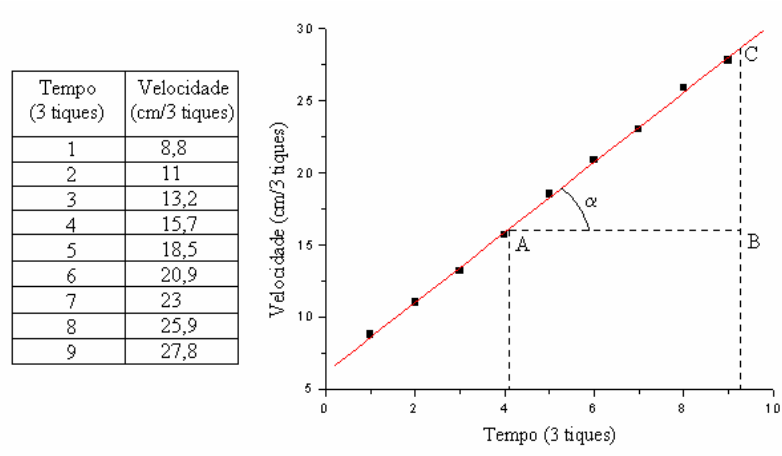

Figura 11. Resultados de uma experiência realizada conforme os procedimentos apresentados na parte 1 , de acordo com a Figura 8.

A aceleração da gravidade $=\mathrm{g}=\operatorname{tga}=\frac{C B(\mathrm{~cm} / \text { 3tiques })}{A B(3 \text { tiques })}$.

O coeficiente angular da reta da Figura 11 fornece o seguinte valor para a aceleração da gravidade:

$\mathrm{g} \cong 2,42 \mathrm{~cm} /(3 \text { tiques })^{2}$.

\section{Parte 2}

Como foi dito, o movimento uniforme da fita pode ser estudado analisando-se os pontos nela marcados. No mecanismo apresentado na Figura 10, usamos uma fita (correia) com $203 \mathrm{~cm}$ para ser marcada com velocidade constante. Nela, analisamos um espaço marcado de $141 \mathrm{~cm}$, encontrando um total de 400 pontos. Conhecendo o tempo total gasto pela fita ao completar uma volta (@ 9,73s),pudemos encontrar a velocidade média desse movimento em intervalos definidos de 50 pontos marcados. Nessa experiência foram usadas duas pilhas de $1,5 \mathrm{~V}$, ou seja, totalizando $3 \mathrm{~V}$.

O gráfico construído da velocidade em função do tempo deve dar uma reta paralela ao eixo do tempo. Como exemplo, apresentamos abaixo uma tabela e um gráfico dos resultados da fita acima mencionada:

\begin{tabular}{|c|c|c|c|c|}
\hline $\mathbf{n}^{\mathbf{0}}$ & $\mathbf{n}^{\mathbf{0}}$ de & $\begin{array}{c}\text { Espaço } \\
\text { pontos }\end{array}$ & $\begin{array}{c}\text { Tempo } \\
\text { aproximado }\end{array}$ & $\begin{array}{c}\text { Velocidade } \\
\text { da fita }(\mathbf{c m} / \mathbf{s})\end{array}$ \\
\hline 1 & 50 & 17,7 & 0,847 & 20,9 \\
\hline 2 & 50 & 17,4 & 0,847 & 20,5 \\
\hline 3 & 50 & 17,7 & 0,847 & 20,9 \\
\hline 4 & 50 & 17,6 & 0,847 & 20,8 \\
\hline 5 & 50 & 17,7 & 0,847 & 20,9 \\
\hline 6 & 50 & 17,5 & 0,847 & 20,7 \\
\hline 7 & 50 & 17,6 & 0,847 & 20,8 \\
\hline 8 & 50 & 17,7 & 0,847 & 20,9 \\
\hline
\end{tabular}

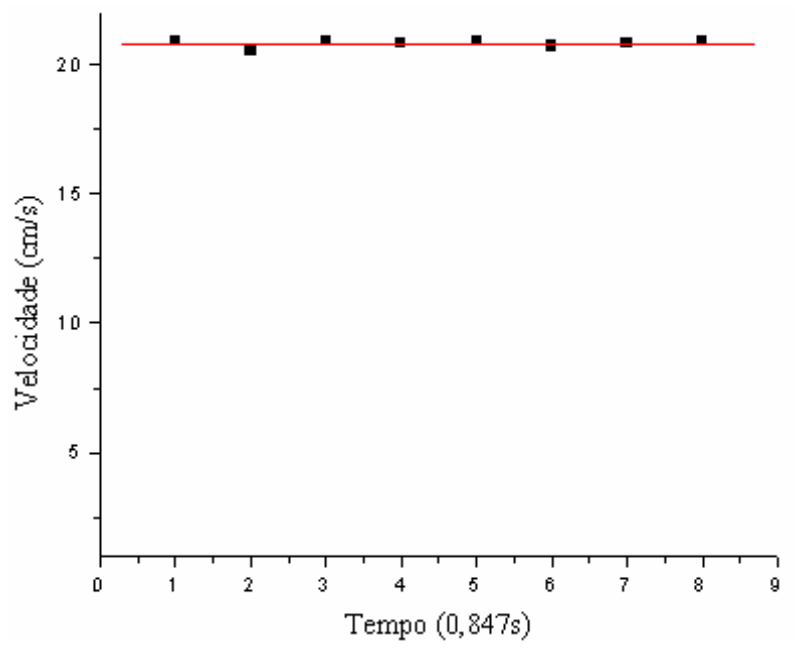

Figura 12 - Gráfico de um movimento uniforme.

\section{Parte 3}

Com o mecanismo apresentado na Figura 10, aproximamos o valor da frequiência de nosso marcador para 60 hertz ao encontrarmos, em repetidas experiências, valores que oscilaram entre 58,9 a 61,2 hertz.

Utilizando os resultados mostrados na tabela da Figura 11, fizemos as conversões de 3 tiques em segundos obtendo a seguinte tabela e gráfico (Figura 13). 

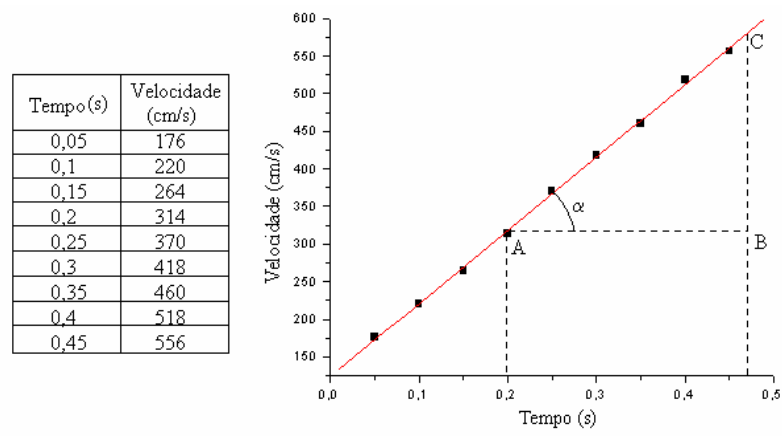

Figura 13 - Resultado obtido pela conversão, na Figura 11 , de 3 tiques em segundos.

O coeficiente angular da reta desse gráfico fornece um valor de $970 \mathrm{~cm} / \mathrm{s}^{2}$ (ou $9,7 \mathrm{~m} / \mathrm{s}^{2}$ ) para a aceleração da gravidade.

Na tabela abaixo, estão apresentados alguns valores típicos que podem ser encontrados com o aparelho, se forem seguidos os pormenores sugeridos no texto.

Tabela 1. Resultados obtidos para o valor da aceleração da gravidade local.

\begin{tabular}{c|c}
\hline $\mathbf{n}^{\mathbf{o}}$ da fita & $\mathbf{g}\left(\mathbf{c m} / \mathbf{s}^{\mathbf{2}}\right)$ \\
\hline 1 & 947,27 \\
\hline 2 & 925,82 \\
\hline 3 & 970 \\
\hline 4 & 902,18 \\
\hline 5 & 931,64 \\
\hline 6 & 932,73 \\
\hline 7 & 934,91 \\
\hline 8 & 964 \\
\hline 9 & 918,06 \\
\hline 10 & 960,73
\end{tabular}

Essa tabela nos dá, para dez experimentos realizados, valores aproximados da média aritmética e do desvio padrão de $938,7 \mathrm{~cm} / \mathrm{s}^{2}$ e $20,5 \mathrm{~cm} / \mathrm{s}^{2}$, respectivamente, para a aceleração da gravidade, $o$ que indica um erro em relação ao valor de $980 \mathrm{~cm} / \mathrm{s}^{2}$, ou $9,8 \mathrm{~m} / \mathrm{s}^{2}$, de $5 \%$.

\section{Conclusão}

Este trabalho apresentou um marcador de tempo alternativo, que pode ser construído com materiais facilmente encontrados no comércio, visando a substituir o antigo marcador de tempo comercializado pela Funbec. Juntamente com o marcador de tempo, apresentou-se um mecanismo simples para estudos de movimentos uniformes, que supera em qualidade experimental aquele da Funbec que, nesse caso, é manual, o que dificulta a realização desse tipo de movimento.

Espera-se que esta alternativa seja uma solução para o professor interessado num experimento de cinemática com as características do aparelho aqui sugerido.

\section{Referência}

FUNBEC. Laboratório Portátil de Física para o ensino do médio ( $2^{\circ}$ grau $)$ : manual de experimentos para o professor. São Paulo: EDART, 1977. 
